EESTI NSV TEADUSTE AKADEEMIA TOIMETISED. IX KÖIDE

FOOSIKALIS-MATEMAATILISTE JA TEHNILISTE TEADUSTE SEERIA, 1960, NR. 3

ИЗВЕСТИЯ АКАДЕМИИ НАУК ЭСТОНСКОЙ ССР. ТОМ IX СЕРИЯ ФИЗИКО-МАТЕМАТИЧЕСКИХ И ТЕХНИЧЕСКИХ НАУК. 1960, № 3

\title{
О СПЕКТРАЛЬНО-АНАЛИТИЧЕСКОМ ОПРЕДЕЛЕНИИ ЛЕГКИХ АРОМАТИЧЕСКИХ УГЛЕВОДОРОДОВ В ПРОДУКТАХ ПЕРЕГОНКИ ЭСТОНСКОГО ГОРЮЧЕГО СЛАНЦА
}

\author{
и. $\mathrm{APPO}$ \\ о. ЭИЗЕН,
}

кандидат технических наук

Ароматические углеводороды приобрели в настоящее время существенное значение как сырье для производства новых синтетических волокон, пластмасс и лаков. В Эстонской ССР единственной отраслью промышленности, производящей ароматические соединения, является сланцеперерабатывающая промышленность. Отсюда вытекает необходимость детального изучения химического состава продуктов перегонки горючего сланца, что позволит дать оценку встречающимся в продуктах перегонки ароматическим углеводородам с точки зрения применения их в современной химической промышленности.

Одним из наиболее быстрых и современных методов определения ароматических углеводородов является метод спектрального анализа.

Первые попытки спектрально-аналитического определения ароматических соединений в продуктах перегонки сланца относятся уже к начальному периоду развития сланцеперерабатывающей промышленности. Так, в 1932 году Краниг ['], производя опыты по определению бензола в сланцевом бензине, обнаружил, что примененная методика не дала положительных результатов, так как спектр бензола скрывался фоном, вызванным многочисленными примесями.

Теперь, когда методы спектрального анализа и анализа бензинов усовершенствованы, настало время возобновить работы по изучению возможностей применения спектрального анализа при определении ароматических углеводородов в сланцевом бензине.

Методы спектрального анализа при исследовании углеводородной части сланцевой смолы применялись до сих пор главным образом с целью идентификации ароматических углеводородов средних и тяжелых фракций смолы $\left.{ }^{2-4}\right]$. О количественной характеристике продуктов перегонки эстонского горючего сланца в литературе встречаются лишь отдельные упоминания [].

В настоящее время наиболее распространены методы спектрального анализа, основанные на исследовании спектров поглощения в ультрафиолетовой области, а также спектров комбинационного рассеяния света. При определении структуры исследуемых смесей и выявлении индивидуальных соединений иногда необходима и инфракрасная спектрография. Все эти разновидности спектрального анализа могут быть использованы при исследовании сланцевой смолы и должны применяться в тесном сочетании.

В качестве сырья для химической промышленности наиболее ценную часть из ароматических углеводородов представляют соединения с более легким молекулярным весом - бензол, толуол и ксилолы. В связи с этим в ходе настоящего исследования особое внимание уделялось определению ароматических углеводородов, температура кипения которых не превышает $160^{\circ}$. 
Исходными продуктами исследования служили легкие фракции смолы различных сланцеперегонных установок, действующих в сланцеперерабатывающей промышленности Эстонской ССР (табл. 1).

Таблица 1

Характеристика исходных смол

\begin{tabular}{|c|c|c|c|c|}
\hline Показатели & $\begin{array}{c}\text { Пропорци- } \\
\text { ональная смесь } \\
\text { легких продук- } \\
\text { тов туннельных } \\
\text { печей }\end{array}$ & $\begin{array}{c}\text { Сырой бензин } \\
\text { вращающихся } \\
\text { реторт }\end{array}$ & $\begin{array}{l}\text { Газбензин ка- } \\
\text { мерных печей }\end{array}$ & $\begin{array}{c}\text { Легкое масло } \\
\text { установки с } \\
\text { твердым тепло- } \\
\text { носителем }\end{array}$ \\
\hline $\begin{array}{l}\text { Удельный вес } d_{4}^{20} \\
\text { Содержание фенолов, } \\
\text { об. \% } \\
\text { Содержание серы } \\
\text { Пределы кипения: } \\
\text { начало кнпения, }{ }^{\circ} \mathrm{C} \\
10 \% \text { выкипает до }{ }^{\circ} \mathrm{C} \\
50 \% \text { ", , } \\
90 \% \text {, }\end{array}$ & $\begin{array}{l}0,8208 \\
4,8 \\
1,05\end{array}$ & $\begin{array}{l}0,7815 \\
\\
3,0 \\
1,33 \\
51 \\
83 \\
141 \\
254\end{array}$ & $\begin{array}{l}0,8286 \\
0,1 \\
1,07\end{array}$ & $\begin{array}{l}0,8349 \\
9,0 \\
1,07\end{array}$ \\
\hline
\end{tabular}

Изучаемая смола подвергалась обесфенолированию $10 \%$-ным водным раствором $\mathrm{NaOH}$ и разделялась в колонне с 60 теоретическими тарелками на бензольную, толуольную, ксилольную и пропил-бензольную фракции.

Для определения ароматических углеводородов, содержащихся в полученных фракциях, применялись ультрафиолетовая спектрография и метод комбинационного рассеяния.

Сравнение обоих методов показывает, что преимуществом метода комбинационного рассеяния служит спектр, состоящий из многочисленных отдельных линий, что позволяет осуществить спектральный анализ и в случае более сложных смесей. Недостатками его являются необходимость иметь при проведении анализа большое количество пробы (68 мл), весьма длительное время выдержки при фотографировании спектра и неудобство впайки пробы в кювет.

Преимуществом метода ультрафиолетового спектрального анализа является возможность работать при низкой концентрации изучаемого вещества в небольшом количестве пробы и получить точные результаты при значительной быстроте анализа. Из недостатков метода следует назвать плоское и с малым количеством максимумов изображение спектра, вследствие чего уже в двух- и трехкомпонентных системах непосредственное определение изучаемого вещества зачастую невозможно.

Анализ по методу комбинационного рассеяния проводился с помощью спектрографа ЙСП-51 без предварительной подготовки изучаемых фракций. Исключение составили пробы, в которых содержание изучаемых ароматических соединений оказалось слишком низким для непосредственного определения. В этом случае обогащение пробы проводилось с помощью хроматографирования на силикагеле. Так, хроматографировались пробы, полученные с установок, работающих при низкой температуре пиролиза (туннельные печи, вращающиеся реторты и др.).

При анализе методом комбинационного рассеяния света применялся способ, разработанный Ландсбергом и др. [5]. Полученные результаты представлены в табл. 2.

По сравнению с методом комбинационного рассеяния применение ультрафиолетового спектрального анализа создает предпосылки для ускорения анализа. В связи с этим проводился ряд опытов с целью выяс- 


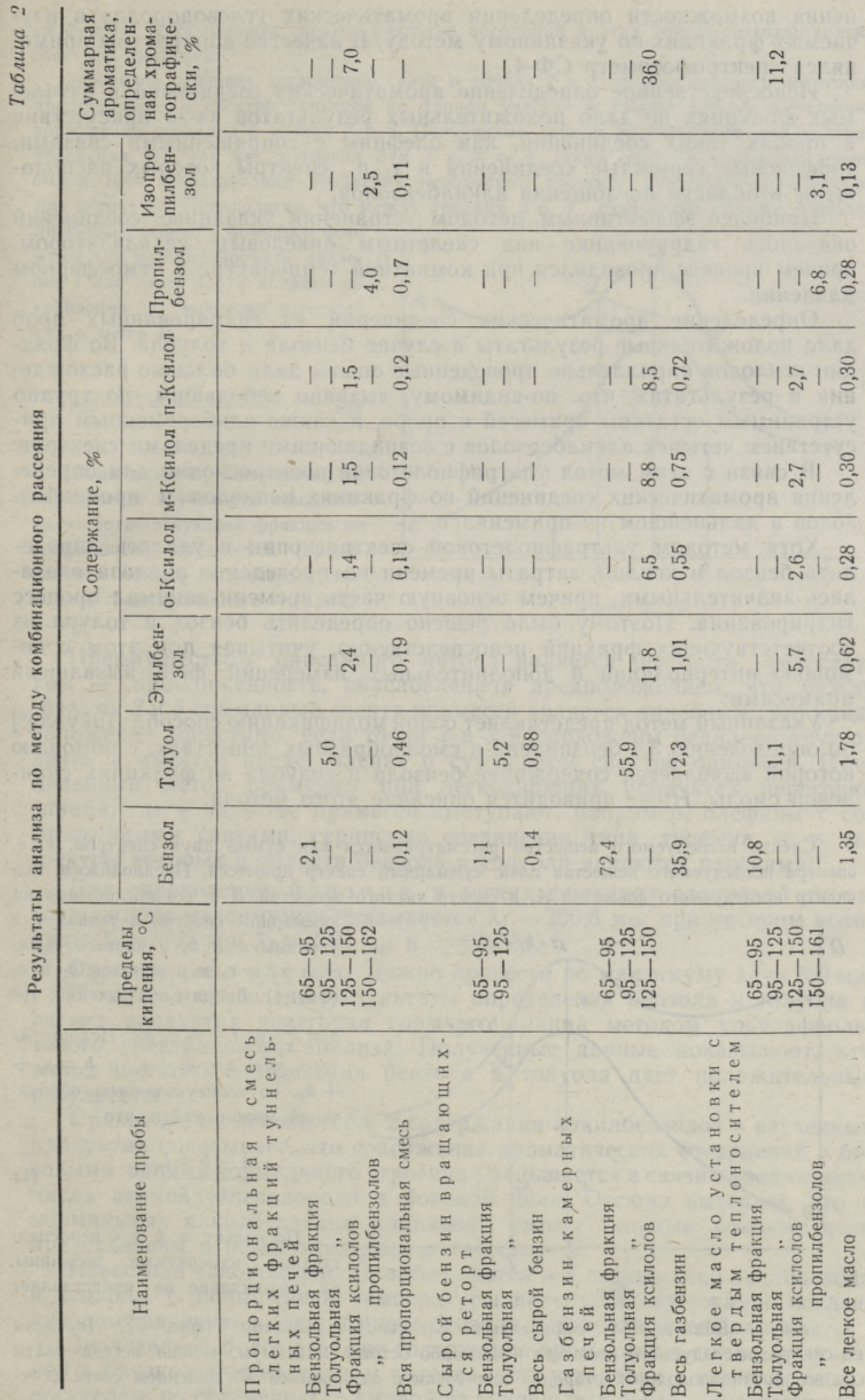


нения возможности определения ароматических углеводородов в изучаемых фракциях по указанному методу. В качестве аппаратуры применялся спектрофотометр СФ-4.

Непосредственное определение ароматических соединений в изучаемых фракциях не дало положительных результатов из-за присутствия в пробах таких соединений, как олефины с сопряженными связами, тиофеновые сернистые соединения и т. п., спектры которых расположены в области поглощения алкилбензолов.

Наиболее эффективным методом устранения указанных соединений оказалось гидрирование над скелетным никелевым катализатором, причем процесс проводился при комнатной температуре и атмосферном давлении.

Определение ароматических соединений из гидрированных проб дало положительные результаты в случае бензола и толуола. Во фракции ксилолов параллельно проведенные опыты дали большие расхождения в результатах, что, по-видимому, вызвано небольшим, но трудно устранимым остатком примесей в пробе, а также одновременным присутствием четырех алкилбензолов с совпадающими пределами спектров.

В связи с этим метод ультрафиолетовой спектроскопии для определения ароматических соединений во фракциях ксилолов и пропилбензолов в дальнейшем не применялся.

Хотя методом ультрафиолетовой спектроскопии и удалось определить бензол и ксилол, затраты времени на проведение анализа оказались значительными, причем основную часть времени занимал процесс гидрирования. Поэтому было решено определить бензол и толуол из соответствующих фракций непосрелственно, учитывая при этом с помощью интерполяции и дополнительных измерений фон, вызванный примесями.

Указанный метод представляет собой модификацию способа Дикуна [ $\left.{ }^{6}\right]$ по определению 3,4-бензпирена в смолообразных веществах, с помощью которой выявляется содержание бензола и толуола во фракциях сланцевой смолы. Ниже приводится описание этого метода.

Спектр исследуемого вещества рассматривается как сумма двух спектров, т. е. спектра исследуемого вещества плюс суммарный спектр примесей. Предположим, что спектр исследуемого вещества $A$, а спектр чистого вещества $B$ и что поглощения на

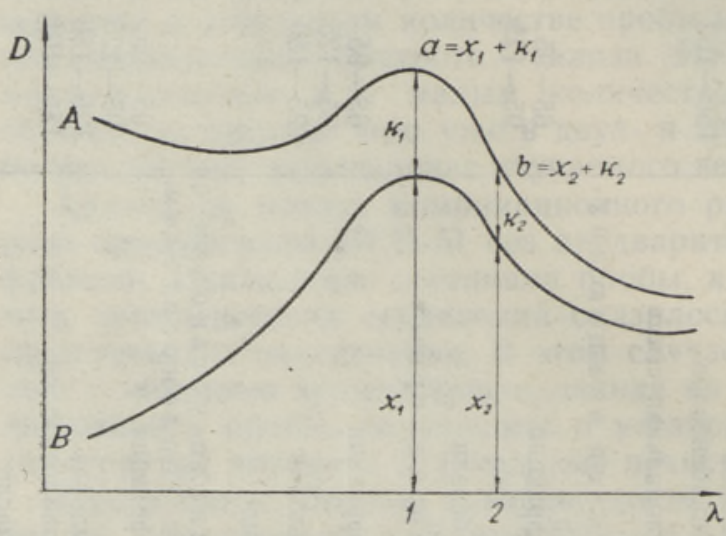

Фиг. 1. суммарном спектре в точках 1 и 2 равны $a$ и $b$, у чистого вещества $x_{1}$ и $x_{2}$ и у примеси $k_{1}$ и $k_{2}$ (фиг. 1). Вводнм обозначения, что $c=\frac{x_{2}}{x_{1}}$ и $l=k_{2}-k_{1}$. Исходя из того, что $a=x_{1}+k_{1}$ и $b=x_{2}+$ $+k_{2}$, из вышеуказанных обозначений можно найти, что

$$
x_{1}=\frac{a-b+l}{1-c}
$$

Поскольку $a \cdot b$ и $c$ непосредственно измеряемые величины, их нахождение не представляет

трудности. Величину $l$ определяют следующим образом (фиг. 2). Выбирая в спектре исследуемого вещества какой-либо острый максимум, можно всегда найти на его противоположных сторонах две точки с одинаковым поглощением света (точ- 
ки 2 и 3). В суммарном спектре различие абсорбции в этих точках вызвано только спектром примесей.

Определив величину поглощения света в точках 2 и 3 , можно получить некоторое представление о спектре примесей на данном участке и точные данные о различии поглощения примесей в точках 2 и 3 . Полученные данные недостаточны для решения уравнения (1), так как в точках 2 и $3 x_{1}=x_{2}$ и, таким образом, уравнение теряет смысл. Для использования уравнения необходимо провести дополнительное измерение в точке 1 . Предполагая, что между точками 2 и 3 суммарный спектр является линейным, можно с помощью фор-

мулы (2) интерполировать значение $l$ для точек $l$ и 2 и найти из уравнения (1) величину поглощения в точке 1 :

$$
l=\frac{(b-d)\left(\lambda_{2}-\lambda_{1}\right)}{\lambda_{2}-\lambda_{3}}
$$

Зная величину поглощения $x_{1}$, определение изучаемого компонента в соответствующей фракции не представляет трудностей (провести его можно, например, с помощью градуированного графика).

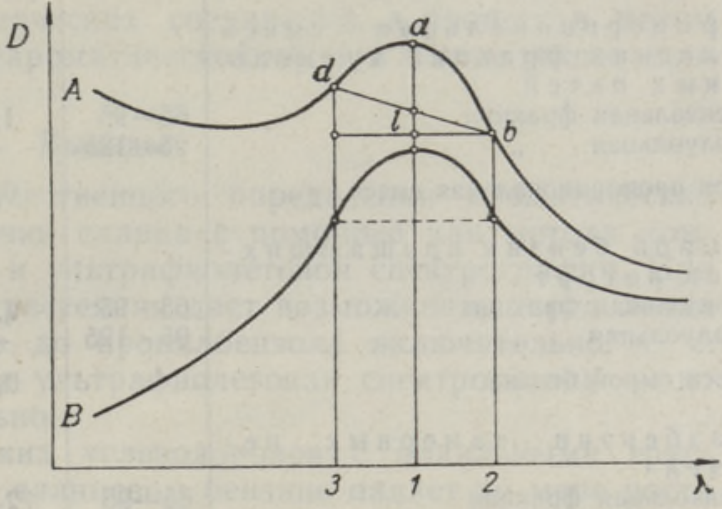

Фиг. 2.

Преимуществом описанного метода является быстрота, недостатком - приближенность, обусловленная предположением, что между точками 2 и 3 суммарный спектр примесей является линейным. Это предположение допустимо, если точки 2 и 3 расположены недалеко друг от друга и имеется представление о суммарном спектре примесей. Приведенный метод применим при легкокипящих продуктах перегонки сланца, где в качестве примесей выступают, например, олефины с сопряженными связями, сернистые соединения типа тиофена и т. п., спектры которых в области бензола и толуола являются плоскими.

Для определения бензол а в легких фракциях сланцевой смолы подходящим максимумом оказывается $\lambda_{1}=260,8$ м $\mu$, при котором величины $\lambda_{2}=262 \mathrm{м} \mu, \lambda_{3}=260$ м $\mu$ и $c=0,554$.

Определение тол уол а можно провести по максимуму $\lambda_{1}=269$ м $\mu$.

В табл. 3 приведены результаты определения бензола и толуола в легких продуктах перегонки горючего сланца методом ультрафиолетового спектрального анализа. Полученные данные показывают, что метод прямого определения бензола и толуола дает положительные результаты.

Сравнение на основе табл. 2 содержания алкилбензолов в изученных продуктах показывает, что содержание ароматических соединений с боковыми цепями нормального строения уменьшается в связи с увеличением числа атомов углеводорода в боковой цепи. Отсюда вытекает, что в нормальных алкилбензолах сланцевой смолы длинные боковые цепи представлены в незначительном количестве.

Известная закономерность наблюдается и в содержании этилбензола и ксилола. С повышением температуры перегонки содержание последних по сравнению с содержанием бензола и толуола уменьшается.

Значительно более высокое содержание ароматики в смоле, полученной в близком температурном интервале из установки с твердым теплоносителем, по сравнению со смолой из туннельных печей и вращающихся 


\section{Результаты ультрафиолетового спектрального анализа}

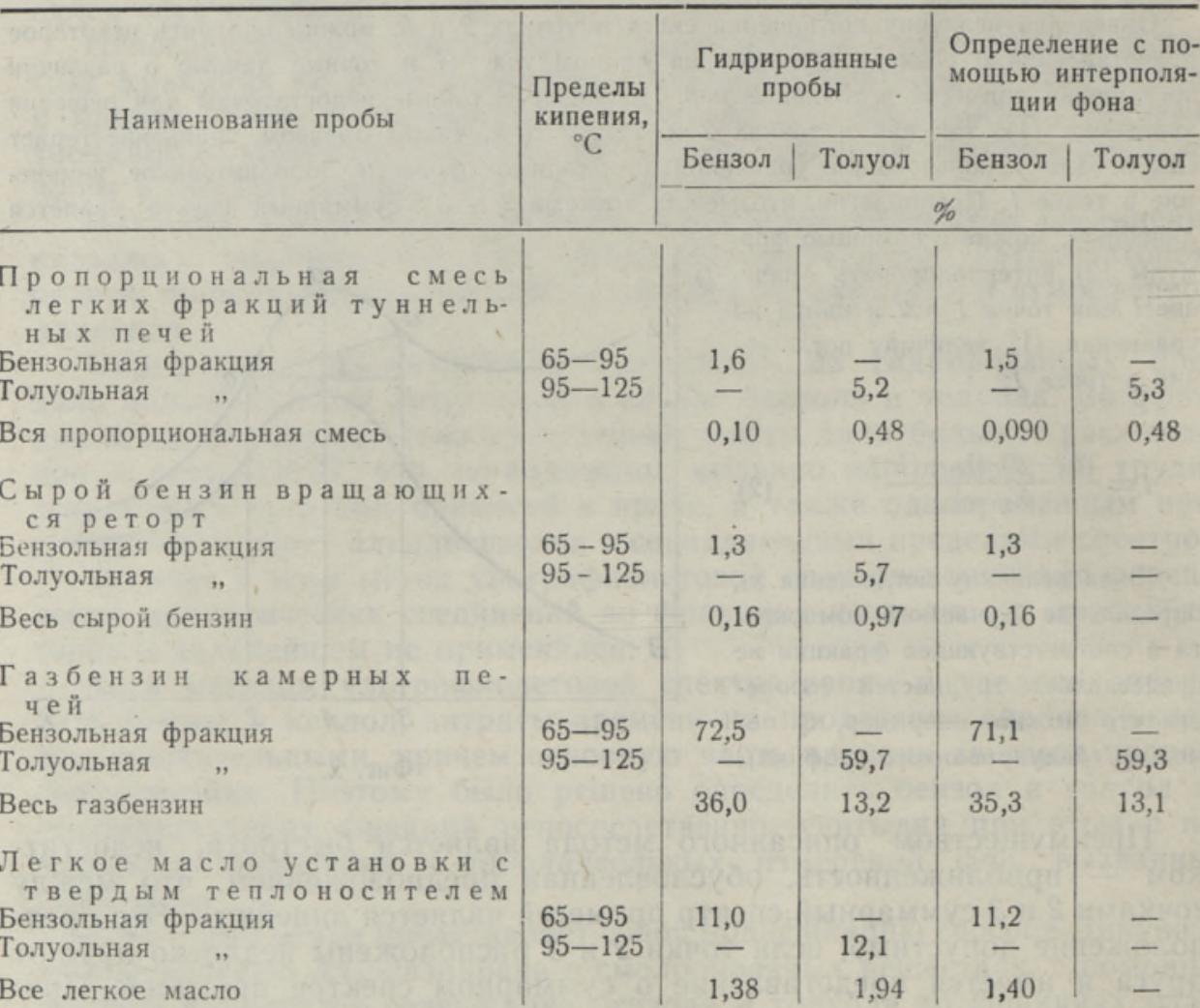

реторт объясняется частичным перегревом сланца при контакте его с твердым теплоносителем.

По содержанию бензола и толуола наиболее близкими к газбензину

Таблица 4

Содержание ароматических соединений в продуктах перегонки разных сланцев

\begin{tabular}{|c|c|c|c|c|c|c|c|c|}
\hline \multirow[b]{2}{*}{ Продукт перегонки } & \multirow[b]{2}{*}{ 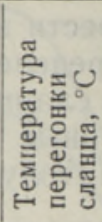 } & \multicolumn{7}{|c|}{ Содержание, \% } \\
\hline & & 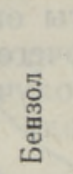 & 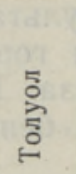 & 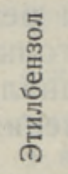 & 总 & 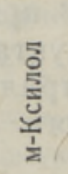 & 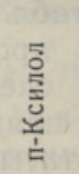 & 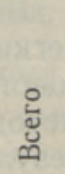 \\
\hline $\begin{array}{r}\text { Фракция смолы американского } \\
\text { сланца с пределом кипення }\end{array}$ & & & & & & & & \\
\hline до $150^{\circ} \mathrm{C}\left[{ }^{10}\right]$ & 650 & 18,0 & 16,3 & & & & & 42,1 \\
\hline Го же & $\begin{array}{l}815 \\
750\end{array}$ & $\begin{array}{l}54,2 \\
36,3\end{array}$ & $\begin{array}{l}27,7 \\
15,9\end{array}$ & $\underline{1,5}$ & - & 8,2 & - & 91,6 \\
\hline $\begin{array}{l}\text { 10 же после пиролиза при } \\
700^{\circ} \text { С [9** } \\
\text { Газбензин камерных печей (оп- } \\
\text { ределено в Институте химии } \\
\text { АН ЭССР) }\end{array}$ & 750 & 37,6 & 15,8 & 1,01 & 0,55 & 0,75 & 0,72 & 59,0 \\
\hline
\end{tabular}

* Содержание ароматических соединений пересчитано на исходный бензин 
камерных печей являются фракции смолы американского сланца [10], полученные при высокотемпературном пиролизе (табл. 4). Как видно из этих данных, фракция смолы этого сланца содержит в отличие от газбензина камерных печей сравнительно большое количество ксилолов, что обусловлено, очевидно, различием как самого сланца, так и применяемых систем перегонки.

Сравнение газбензина камерных печей с данными, полученными Кобыльской [9] для пиролизата бензина того же происхождения (табл. 4), показывает, что в результате процесса пиролиза практически не образуется дополнительно ароматических соединений, а процесс в целом представляет собой крекинг неароматической части в легкие углеводороды и газ.

\section{Выводы}

1. Разработан метод количественного определения ароматических соединений продуктов перегонки сланца с помощью как метода комбинационного рассеяния, так и ультрафиолетовой спектрографии. При этом метод комбинационного рассеяния дает возможность определения ароматических углеводородов до пропилбензола включительно, т. е. с пределом кипения 160', а ультрафиолетовая спектроскопия - до бензола и толуола включительно.

2. Количество ароматических углеводородов с алкильными группами нормального строения в сланцевом бензине падает по мере роста длины боковой цепи. Следовательно, в высоких алкилбензолах с цепями нормального строения, полученных путем перегонки сланца, длинные боковые цепи представлены в незначительном количестве.

3. Из продуктов, полученных на сланцеперегонных установках, работающих на смоляном режиме, наиболее высокое содержание ароматических соединений имеют продукты перегонки установки с твердым теплоносителем. Соотношение суммарного содержания бензола и толуола (в пересчете на сланец) в продуктах перегонки установки с твердым теплоносителем, туннельных печей и врашающихся реторт составляет соответственно $1: 0,24: 0,25$.

\section{Л ИТ Е Р А Т Р А}

1. J. K r a n ig, Keemia teated, kd. I, nr. 2, 1932, lk. 65-68.

2. Е. И. Томина, К. Б. Чернышева, Е. М. Д ементьева, Химия и технология продуктов переработки сланцев, вып. 2, Гостоптехиздат, Л., 1951, стр. 145.

3. О. Г. Эй зен, Об определении простого ароматического эфира бензо- $\beta$-нафтол2,3- $\boldsymbol{d}$-фурана в сланцевой смоле, Тр. Таллинск. политехн. ин-та, сер. А. № 97,1957 .

4. О. Г. Эй зен, И. Х. Ар ро, Химия и технология топлива и масел, № 11, 1957, стр. 39.

5. Г. С. Л раметры спектров комбннационного рассеяния углеводородов, Изд. АН СССР, M., 1956.

6. П. П. Д и кун, Вопр. онкологии, № 4, 1955, стр. 34 .

7. W. Foerst [Red.], Verein Deutscher Chemiker, Neuere Methoden der Präparativen Organischen Chemie I, Chemie Verlag Berlin, 1943.

8. Б. М. Бо гослов с ки й, 3. С. К а з а ков а, Скелетные катализаторы, их свойства и применение в органической химии, Госхимиздат, М., 1957.

9. М. В. Кобыльск ая, С. С. Семенов, Е. В. Глущенков а, З. Ф. Шульм а н, Химия и технология горючих сланцев и продуктов их переработки, вып. 7, Гостоптехиздат, Л., 1959, стр. 207.

10. G. U. D i n nee n, J. R. S m ith and C. W. B a iley, Product Composition of High Temperature Shale Oil, Ind. and Eng. Chem., No. 11, 1952, p. 2647. 


\title{
EESTI POLEVKIVI UTTEPRODUKTIDE KERGETE AROMAATSETE SUUSIVESINIKE SPEKTRAALANALUUTILISEST MÅRAMISEST
}

\author{
I. Arro \\ o. Eisen, \\ tehnikakandidaat
}

\section{Resümee}

Pōlevkivi termilise lagundamise produktid, mis saadi mitmesugustel uttetemperatuturidel, destilleeriti bensooli, toluooli, ksüloolide ja propüülbensooli fraktsioonideks. Viimastes määrati aromaatsed süsivesinikud kvantitatiivselt, kusjuures kasutati Raman'i ja ultraviolett-spektraalanalüüsi.

Määramiste käigus uuriti spektraalmeetodite sobivust põlevkivi utteproduktide analüüsimiseks. Töötati välja pōlevkivibensiini kergemate aromaatsete süsivesinike individuaalse kvantitatiivse määramise meetodid.

Analüüsimisel selgus, et õlirežiimil töötavaist utteseadmeist on kõrgeima kergete aromaatsete ühendite sisaldusega tahkel soojusekandjal saadud pürolüüsiproduktid. Tunnelahjudel ja pöörlevatel retortidel toodetud bensiinis ei ole aromaatsete süsivesinike sisalduses suuri erinevusi. Eesti NSV Teaduste Akadeemia
Keemia Instituut
Saabus toimetusse

16. X 1959

\section{SPEKTRALANALYTISCHE BESTIMMUNG LEICHTER AROMATISCHER KOHLENWASSERSTOFFE IN DEN SCHWELPRODUKTEN DES ESTNISCHEN BRENNSCHIEFERS}

\author{
I. Arro, O. Eisen
}

\section{Zusammenfassung}

Bei verschiedenen Schwelungstemperaturen erhaltene Produkte der thermischen Zersetzung des Brennschiefers wurden zu Fraktionen des Benzols, des Toluols, des Xylois und des Propylbenzols destilliert. In diesen wurden die aromatischen Kohlenwasserstoffe durch Ramans und Ultraviolett-Spektralanalyse quantitativ bestimmt.

Im Gange der Arbeiten wurde die Tauglichkeit spektraler Methoden für die Analyse von Schwelprodukten untersucht. Es wurden Methoden für die individuelle quantitative Bestimmung der leichteren aromatischen Kohlenwasserstoffe des Brennschieferbenzins ausgearbeitet.

Die Analysen ergaben, dass von den Schwelanlagen mit Olregime die mit festem Wärmeträger versehenen Anlagen diejenigen sind, die Pyrolyseprodukte mit dem höchsten Gehalt an leichten aromatischen Verbindungen geben. Tunnelofenbenzin und Drehretortenbenzin weisen in bezug auf den Gehalt an aromatischen Kohlenwasserstoffen keine wesentlichen Unterschiede auf.

Institut für Chemie

der Akademie der Wissenschaiten der Estnischen SSR
Eingegangen am 16. Okt. 1959 